\title{
Allogeneic Hematopoietic Cell Transplantation for Paroxysmal Nocturnal Hemoglobinuria
}

\author{
Markiewicz Miroslaw, Koclega Anna, Sobczyk-Kruszelnicka Malgorzata, \\ Dzierzak-Mietla Monika, Zielinska Patrycja, Frankiewicz Andrzej, \\ Bialas Krzysztof and Kyrcz-Krzemien Slawomira \\ Medical University of Silesia, Department of Hematology and BMT, Katowice, \\ Poland
}

\section{Introduction}

Paroxysmal nocturnal hemoglobinuria / $\mathrm{PNH} /$ is an acquired, clonal disorder of hematopoietic stem cell, characterized by intravascular hemolysis and manifested by episodes of hemoglobinuria, life-threatening venous thromboses, bone marrow failure and smooth muscle dystonias. The triad of hemolytic anemia, pancytopenia and thrombosis makes PNH a truly unique clinical syndrome. The disease can arise de novo or in the setting of acquired aplastic anemia (Robert A. Brodsky, 2008). The name of the disease refers to the occurrence of hemoglobinuria responsible for red or dark brown urine. Hemoglobinuria in patients with PNH very often appears after awakening and is due to intravascular lysis of red blood cells that are abnormally sensitive to the complement attack (Bessler and Hiken, 2008). PNH is unique as it is an acquired hemolytic disorder resulting from abnormality of the red cell. Almost all other acquired hemolytic conditions are due to an extrinsic attack on the red cells, eg. antibody- mediated or mechanical hemolysis (Hillmen, 2008). So it is not surprising that this rare disease (the estimated incidence of 2 to 5 new cases per million inhabitants (Brodsky, 2008) has been fascinating scientists for almost 150 years. The first clear and detailed clinical description of "intermittent haematuria" in an anemic patient was given by Wiliam Gull in 1866. Dr. Paul Strubling recognized the urinary pigment as haemoglobin and called this sign "paroxysmal haemoglobinuria" in 1882. He has developed the hypothesis that the erythrocytes of $\mathrm{PNH}$ are abnormally sensitive to hemolysis when the plasma is acidified during sleep because of carbon dioxide and lactic acid accumulation as a result of slower circulation (Parker, 2008). His work was largely ignored until Marchiafava reported a case in Italy 29 years later. In 1931 Michelli published further observations and used the term " splenomegalic hemolytic anemia with hemoglobinuria and hemosiderinuria Marchiafava-Michelli type"- hence the name Marchiafava-Michelli disease. Early in the 20th century Van der Bergh showed that erythrocytes from PNH patients underwent lysis in acidified serum and he suspected that complement played a role in this abnormality. In 1944, Dacie noted a possible association with aplasia and suggested that $\mathrm{PNH}$ is an acquired clonal dysfunction affecting hematopoietic stem cells occurring due to their somatic mutation (Johnson RJ et al, 2002). The mechanism of clonal dominance in PNH remains unknown. 


\section{Pathogenesis and classification}

$\mathrm{PNH}$ is not only interesting for hematologists, but it is also very important problem for neurologists, nephrologists, gastroenterologists, pediatricians (about $10 \%$ of patients are younger than 21 years) and gynecologists $(25 \%$ of the cases are diagnosed during pregnancy (Parker et al. 2005).

PNH is caused by an acquired somatic mutation of the PIG-A gene located on the short arm of the $\mathrm{X}$ chromosome in multipotent hematopoietic stem cell. Most PIG-A mutations are small insertions or deletions that result in a frame-shift in the coding region and consequently a shortened non-functional GPI product (Brodsky, 2008). Due to its localization on the $X$ chromosome and due to $\mathrm{X}$ inactivation in the female somatic cells, only one mutation is required in either males or females to abolish the expression GPI-linked proteins. To date over 180 mutations have been identified in the PIG-A gene in blood cells from patients with PNH (Hillmen, 2008). Small to moderate PNH clones are found in up to $70 \%$ of patients with acquired aplastic anemia, demonstrating a patho-physiological link between these disorders (Schrezenmeier et al. 1995; Dunn DE et al. 1999; Mukhima GL et al. 2001; Wang H et al, 2002). What is more, many of aplastic anemia patients exhibit expansion of the PIG-A mutant clone and progress to clinical PNH (Brodsky, 2008). GPI- anchored proteins deficient cells have also been reported in patients with myelodysplastic syndrome (MDS) (Dunn DE et al. 1999; Mukhina Gl et al. 2001; Wang $\mathrm{H}$ et al. 2002). Patients with MDS possessing small PNH populations tend to be classified as having refractory anemia and often have a hypocellular marrow with HLA-DR15 positivity, normal cytogenetics, moderate to severe thrombocytopenia and high likelihood of response to immunosuppressive therapy (Wang H et al. 2002; Nagarajan S et al. 1995; Sugimori C et al. 2006).

PIG-A gene encodes complement-protecting surface proteins which are normally tethered to the cell membrane of erythrocytes, neutrophils and platelets by the GPI anchor (Rosse WF et al. 2004). Two proteins play particularly important role:

- CD55 (DAF- Decay Accelerating Factor) which controls the first steps of the complement cascade by regulating the activity of C3 and C5 convertases (Rosse WF et al. 2004; Johnson RJ et al. 2002; Parker C et al. 2005).

- CD59 (MIRL-Membrane Inhibitor of Reactive Lysis) which inhibits the formation of the Terminal Complement Complex by preventing the incorporation of $\mathrm{C} 9$ in the $\mathrm{C} 5 \mathrm{~b}-8$ complex, thereby preventing the formation of Membrane Attack Complex (MAC or C5b-9) (Rosse WF et al. 2004; Johnson RJ et al. 2002; Parker C et al. 2005).

Defect in PIG-A gene leads to partial or complete deficiency of these protective factors (CD55 and CD59) on the cell surface responsible for susceptibility to the lytic effects of activated complement and intravascular lysis of erythrocytes.

Flow cytometry analysis reveals that all hematopoietic lineages: myeloid, erythroid and lymphoid are involved (Brodsky, 2008).

Glycosylphosphatidyloinositol (GPI) protein deficiency on PNH red cells can be complete (PNH type III cels) or partial (PNH type II cells). Cells with normal levels of GPI proteins on their surface are referred to as type I cells (Fujioka \& Yamada, 1994). The analysis of GPIanchored proteins on the surface of the hematopoietic cells, particularly red cells in $\mathrm{PNH}$ reveals that approximately $40 \%$ of patients have a combination of types I, II, III PNH cells (Hill et al. 2007).

Current classification system has recently been proposed, which divides patients with PNH clones into the following subgroups (Parker C et al. 2005): 
- Classic PNH- patients have clinical evidence of intravascular hemolysis: signs of marrow stimulation- reticulocytosis, high levels of LDH and direct or indirect bilirubin, low concentration of serum haptoglobin, without evidence of another defined bone marrow abnormality.

- $\quad$ PNH in the setting of another bone marrow disorder- patients in this subcategory have clinical and laboratory evidence of hemolysis, but also have or have had a history of a defined underlying marrow abnormality (eg. $\mathrm{PNH} /$ aplastic anemia, $\mathrm{PNH} /$ refractory anemia-MDS).

- Subclinical PNH- patients have no clinical or laboratory evidence of hemolysis. PNH-sc is observed in association with bone marrow failure syndromes, particularly aplastic anemia and refractory anemia-MDS.

The course of the disease is marked by exacerbations of hemolysis of varying severity on top of the chronic hemolysis which exists in these patients. Repeated paroxysmal episodes often necessitate a transfusion. The paroxysms may be triggered by infections, stress, trauma, surgery, pregnancy and drugs.

Intravascular hemolysis is responsible for most symptoms observed in PNH patients. Free hemoglobin released from PNH red cells during intravascular hemolysis can completely deplete haptoglobin and then overflow into the urine resulting in hemoglobinuria (Tabbara, 1992). Once the capacity of this hemoglobin scavenging protein is exceeded, (Parker et al. 2005) consumption of endogenous nitric oxide (NO) ensues. This reduced bioavailability of NO could also promote platelet and endothelial activation, leading to intravascular thrombosis (Rosse WF et al. 2004; Parker C et al. 1996; Rother RP et al. 2005). The occurrence of thrombotic events can sometimes lead to the diagnosis. Venous thrombosis may be recurrent and often occur in uncommon sites (Gralnick HR et al. 1995) such as pre-hepatic veins (Budd-Chiari syndrome), splenic, portal, renal, cerebral or mesenteric veins or inferior vena cava. An increased incidence of arterial thrombosis has also been reported.

Nitric oxide depletion also causes disturbances in the regulation of smooth muscle tone (especially during PNH exacerbations), resulting in abdominal pain, dysphagia and erectile dysfunction- it has been well established that local NO deficiency is one of the major factors responsible for erectile dysfunction (Corbin et al. 2002). Moreover, about $50 \%$ of patients with hemolytic PNH have elevated pulmonary artery systolic pressure (Hill et al 2006).

About $35 \%$ of $\mathrm{PNH}$ patients are presenting symptoms of anemia. It should be distinguished how much of the anemia is a consequence of hemolysis and how much is due to impaired erythropoiesis. Review of the complete blood count is informative, because evidence of thrombocytopenia, leucopenia or both suggests stem cell dysfunction. Marrow failure is likely to be a contributing factor in a patient with $\mathrm{PNH}$ who has anemia with an inappropriately low reticulocyte count.

\section{Diagnostics}

As $\mathrm{PNH}$ is a very rare disease, appropriate choice of patients for $\mathrm{PNH}$ screening is a very important issue. It should include patients with hemoglobinuria, Coombs negative intravascular hemolysis (based on abnormally high serum LDH, especially with iron deficiency), venous thrombosis involving unusual sites, aplastic anemia and refractory anemia. In 1939 Ham and Dingle's historic paper described the first diagnostic test for PNH utilizing the finding that PNH red cells were exquisitely sensitive to hemolysis in the setting of acidified serum, now known as the Ham's test. It has been used to diagnose PNH for 
decades. Other traditional diagnostic tests were sucrose and thrombin lysis tests, cheap and simple to perform, but with decreased sensitivity due to the short half-life of circulating PNH red blood cells (Bessler and Hiken, 2008).

Nowadays flow cytometry is the gold standard method as it is the most sensitive and yields the most quantitative and qualitative information (Parker C et al. 2005). This technique uses specific antibodies directed against antigens normally tethered by GPI to the surface of hematopoietic cells (erythrocytes, granulocytes and monocytes). Analysis of erythrocytes should either precede transfusions or be performed during a period of transfusion abstinence. The results of the analysis for erythrocytes should include the percentage of type I, type II, and type III PNH cells (Parker C et al. 2005). Analysis of granulocytes provides the best estimate of the size of the PNH clone and it is unaffected by red cells transfusion (Bessler and Hiken 2008). Another method used for PNH diagnosis is lack of FLAER (fluorescently labeled inactive toxin aerolysin) binding to GPI anchor on peripheral blood granulocytes. The method cannot be used for the analysis of red blood cells or platelets, thus it might be difficult to perform in severe aplastic anemia due to very low number of circulating granulocytes. PIGA gene mutation analysis, although very specific, is not used for diagnosing PNH. Supportive laboratory tests confirming presence of intravascular hemolysis are helpful, although not diagnostic: increased lactate dehydrogenase (LDH), low haptoglobin, increased unconjugated bilirubin, hemoglobinuria, hemosiderinuria, reticulocytosis and erythroid hyperplasia in the bone marrow.

Median survival in PNH is 10 to 15 years after diagnosis, with a wide range (Brodsky, 2009). Men and women are affected equally and there is no familial tendency. Thrombophilia is a major cause of morbidity and mortality in PNH (Hillmen et al. 1995; Socie G et al. 1996). About $40 \%$ of patients with PNH experience a thrombotic event during the course of disease (Hillmen et al. 1995; Socie G et al. 1996; Ware RE et al. 1992). Risk of developing thrombosis is proportional to the size of the PNH clone (Hillmen P et al. 2007; Hall C et al. 2003; Moyo V et al. 2004; Nishimura J 2004). Population of PNH granulocytes $>50 \%$ predicts an increased risk of thrombosis (Hall C et al. 2003). The cause of thrombotic tendency in PNH is multifactorial. Free plasma hemoglobin may contribute to platelets activation and thrombosis. The effect of free hemoglobin on platelet function is probably through the scavenging of nitric oxide (NO). Reduction of NO generation leeds to increased platelet aggregation (Broekman et al. 1991, Schafer et al. 2004).

Another complication in PNH is bone marrow insufficiency (Hillmen et al. 1995). It has long been known that there is a close correlation between PNH and aplastic anemia.

Renal failure has been recognized as a complication of $\mathrm{PNH}$ for many years. Between $8 \%$ and $18 \%$ of deaths in PNH have been reported to have renal failure as at least a contributing factor (Nishimura JI et al. 2004; Clark DA et al. 1981). The cause of renal failure is probably damage of proximal renal tubules by iron released during intravascular hemolysis (Hillmen 2008).

$\mathrm{PNH}$ is only rarely associated with acute myeloid leukemia. It occurs in approximately $5 \%$ of patients with aplastic anemia. Marrow aplasia predisposes to $\mathrm{PNH}$ and to the leukemic transformation into acute leukemia. In most leukemia patients with PNH who have been studied the leukemic clone has been derived from the PNH clone (Hillmen P et al. 1995). A significant proportion of patients survive for prolonged periods (approximately 25\% surviving over 25 years with blood transfusion support only) and about $10 \%$ to $15 \%$ experiences a spontaneous recovery from $\mathrm{PNH}$ with no sequelae attributable to the disease . A possible hypothesis to explain occasional spontaneous recovery is that intensity of aplastic process that is positively selecting $\mathrm{PNH}$ clones reduces with time. Recovery would 
depend on the presence of normal stem cells capable of regenerating the bone marrow (Hillmen P et al. 1995)

Before initiating treatment of $\mathrm{PNH}$, it is useful to stratify patients into classical or hypoplastic PNH. This can usually be accomplished by obtaining a complete blood and reticulocyte count, LDH determination, peripheral blood flow cytometry and bone marrow examination. Regardless of how patients with small PNH clones are classified (eg. $\mathrm{AA} / \mathrm{PNH}, \mathrm{MDS} / \mathrm{PNH}$ or subclinical PNH), they do not have to and should not be treated, unless symptoms appear. Patients with $\mathrm{PNH}$ clones less than $10 \%$ rarely require clinical intervention, nevertheless they should be monitored closely because expansion of the clone may occur. Monitoring of granulocyte and erythrocyte clone size is sometimes performed every 6 to 12 months. Patients with PNH have an impaired quality of life in comparison with the general population. They suffer from chronic fatique, which seriously compromises their professional and personal lives (Moyo VM et al. 2004). Patients with chronic hemolysis complain of lethargy, malaise, myalgia (Clark DA et al. 1981). The dysphagia and male impotence of PNH appear related to hemolysis (Rosse WF 2000).

\section{Treatment}

PNH patients with either chronic hemolysis or with acute hemolytic exacerbations may be treated with corticosteroids (Rosse WF 1982; Zhao M et al. 2002; Bourants K 1994; Issaragrisil $S$ et al. 1987). Some patients respond rapidly and dramatically to prednisone given in the dose range of $0,25-1,0 \mathrm{mg} / \mathrm{kg}$ per day, but chronic use of corticosteroids may cause adverse effects such as immunosuppression, osteopenia, myopathy, iatrogenic Cushing syndrome, hypertension or in diabetes (Rosse WF 1982). Androgen therapy either alone or combination with steroids has been used successfully to treat anemia in PNH (Rosse WF 1982; Hartman RC 1966), especially caused by the underlying bone marrow failure. Although starting dose of $400 \mathrm{mg}$ twice a day is recommended, a lower dose $(200-400 \mathrm{mg} / 24 \mathrm{~h})$ may be adequate to control chronic hemolysis. Potential complications of androgen treatment include liver toxicy (cholestatic jaundice, peliosis hepatic) prostatic hypertrophy and virilizing effects.

Transfusion therapy, despite improvement of blood hemoglobin, reduces hemolysis by suppressing erythropoiesis. The iron overload that follows repeated transfusion is prevented by the urinary loss of iron due to the hemoglobinuria and hemosiderinuria connected with intravascular hemolysis (Parker $C$ et al. 2005). To prevent transfusion reaction arising from the interaction between donor leukocytes and recipient's antibodies hemofiltration is recommended. Folates supplementation $(5 \mathrm{mg} / 24 \mathrm{~h})$ is recommended to compensate for their utilization associated with increased erythropoiesis consequencing from hemolysis (Parker et al. 2005). Chronic hemosiderinuria and hemoglobinuria may lead to severe iron deficiency despite repeated transfusions, thus $\mathrm{PNH}$ patients often require iron supplementation. $\mathrm{PNH}$ patients with cytopenias often respond to immunosuppressive therapy with anti-lymphocyte globulin and/or ciclosporin, because of associated aplastic anemia.

As the hemolysis of PNH is a consequence of complement- mediated cytolysis, inhibition of complement is a logical approach to therapy (Parker CJ 2003). Eculizumab is a humanized monoclonal antibody that targets complement protein $\mathrm{C} 5$, thereby preventing assembly of the terminal complement complex (also called the Membrane Attack Complex or MAC) during complement activation. Eculizumab is an IgG kappa immunoglobulin with engineered Fc portion that is a hybrid of IgG2 and IgG4 designed to have no downstream activity- thus eculizumab is a purely "blocking" antibody that prevents the cleavage and 
thus activation of C5 (Hillmen, 2008). Eculizumab is highly effective in reducing intravascular hemolysis in $\mathrm{PNH}$, but it does not stop extravascular hemolysis, and it does not treat the bone marrow failure. Thus treatment with eculizumab is most effective in patients with classic PNH- it decreases or eliminates the need of blood transfusion, reduces the risk of thrombosis and improves quality of life (Hillmen et al. 2007; Hillmen et al. 2006; Brodsky RA 2008). Eculizumab has been approvated by FDA for PNH treatment in 2007. Thrombosis is an absolute indication for initiating treatment with eculizumab (Brodsky 2009). Some authors recommend eculizumab for patients with disabling fatigue, transfusion dependency, frequent painful paroxysms, renal insufficiency. Watchful waiting is appropriate for asymptomatic patients or those with mild symptoms (Brodsky and Jones, 2005; Young 2002). Eculizumab therapy shouldn't be initiated in patients with unresolved serious Neisseria menigitidis infection and who are not currently vaccinated against it. Eculizumab is administered intravenously at a dose of $600 \mathrm{mg}$ weekly for first 4 weeks, then 900mg biweekly starting on week 5 (Brodsky 2009). Eculizumab is generally well tolerated, but the most frequent adverse events observed in clinical studies were: headache, nasopharyngitis, back pain, nausea and fatique. Eculizumab increases risk of meningococcal infections, so ideally patients should be vaccinated 2 weeks before commencing eculizumab and re-vaccinated every 2 to 3 years. Patients also need to be instructed to contact doctor immediately if they develop any symptoms suggesting meningococcal infection, such as very high temperatures, a hemorrhagic rash or neck stiffness (Hillmen 2008). Most patients with PNH who are treated with eculizumab will cease to require transfusions. This leads to an increase in the proportion of PNH red cells as they are not destroyed by complement nor diluted by transfusions (Socie $\mathrm{G}$ et al. 2007). In some patients the proportion of PNH red cells may exceed $90 \%$ so if eculizumab is stopped for any reason, it may be followed by a sudden fall in hemoglobin and brisk hemoglobinuria. Patients who receive eculizumab must be educated that they cannot simply miss a scheduled dose of therapy (Hillmen, 2008).

Prophylaxis against thromboembolic events in patients with $\mathrm{PNH}$ is an issue of debate among members of the International PNH Interests Group (Moyo VM et al. 2004; Nishimura et al. 2004; Clark DA et al 1981; Sloand EM, 2000). The relatively high risk of a thromboembolic complications justifies prophylaxis with warfarin in $\mathrm{PNH}$ when over $50 \%$ granulocytes are GPI-AP deficient and there are no contraindications to anticoagulation (Nishimura et al. 2004). Patients with PNH who experience a thromboembolic event should receive high-intensity warfarin therapy (International Normalized Ratio INR 3.0-4.0) or subcutaneous low molecular weight heparin (Parker et al. 2005). Prophylactic anticoagulation with low molecular weight heparin should be initiated in PNH patients with elevated D-dimer levels, during pregnancy and puerperal period and in the perioperative period (Brodsky, 2009). Patients with acute thrombotic events require anticoagulation with heparin. Thrombolytic therapy (McMullin et al. 1994; Sholar et al. 1985) or radiologic intervention (Griffith et al. 1996) should be strongly considered in patients with acute onset of Budd-Chiari syndrome.

\section{Hematopoietic cell transplantation}

Nowadays, the availability of option to prevent complement-dependent hemolysis by use of eculizumab has decreased use of allogeneic hematopoietic cell transplantation (allo-HCT) in $\mathrm{PNH}$. Allo-HCT is the only curative and durable therapy for $\mathrm{PNH}$ which is still recommended for $\mathrm{PNH}$ patients with life-threatening cytopenias, hemolysis or thrombosis, that is not controlled with eculizumab therapy. The decision to perform allo-HCT should 
weigh disease prognosis by incorporating known adverse prognostic factors such as previous history of thrombosis and/or evolution to pancytopenia, against the risk of transplant-related complications. Multiple transplant-related risk factors for hemolysis can be managed without exacerbation of hemolysis during the procedure (Markiewicz et al. 2006). Selection of the appropriate candidate and, equally important, the right time to perform allo-HCT are important questions that need to be answered (Matozs-Fernandez et al. 2009). The fact that the majority of patients undergoing allo-HCT usually already had an extensive transfusion history is an important issue. PNH patients with peripheral cytopenias meeting criteria for severe aplastic anemia are considered good candidates for allo-HCT. Allo-HCT should not be offered as initial therapy for most patients with classical PNH. Exceptions are patients with PNH in countries where eculizumab therapy is not available, primarily due to considerable cost of treatment. Although allogeneic hematopoietic cell transplantation (allo-HCT) offers complete cure of PNH with complete eradication of the $\mathrm{PNH}$ clone, outcomes presented in the past were controversial. Thus it is important to reevaluate results of allo-HCT in PNH. There are few reports on the use of allo-HCT for PNH and nearly all of them include small numbers of patients. Small series and reporting biases make assessment of transplant outcomes difficult. There are few risk factors associated with worse survival: occurrence of thrombosis, progression to pancytopenia, transformation to myelodysplastic syndrome or acute leukemia and thrombocytopenia at diagnosis. Transplants from siblings and especially from unrelated donors performed in the past, before implementation of complete allelic HLA-typing, were based on suboptimal donorrecipient matching. Moreover, improvements of HLA typing, growing experience of transplant teams and better either myeloablative or reduced intensity conditioning and concomitant therapy with introduction of novel antimicrobial agents enabled achieving better outcomes of allo-HCT in PNH. Similar to other allo-HCT transplantation patients, younger age and the availability of a fully HLA-matched sibling donor are favorable prognostic factors.

Proper choice of conditioning regimen is a very important component of treatment with allo-HCT. Eradication of the PNH clone has been achieved with both myeloablative and reduced-intensity conditioning regimens (Matozs-Fernandez et al. 2009; Suenaga et al. 2001). Myeloablative regimens used in $\mathrm{PNH}$ consisted of busulfan and cyclophosphamide or fludarabine, high-dose cyclophosphamide alone or together with total body irradiation (TBI) (Raiola et al. 2000; Woodard et al. 2001). This type of conditioning has been associated with high treatment-related mortality, high-dose cyclophosphamide used alone did not exert a significant effect on PNH clone in the long term (Cho SG et al. 2003). In reduced-intensity conditioning fludarabine has been used with or without TBI or cyclophosphamide, and less often with cladribine, thiotepa, busulfan or melphalan in various combinations (Grosskreutz C et al. 2003). In addition to conditioning anti-thymocyte globulin (ATG, Thymoglobuline) and alemtuzumab (Campath) are used in unrelated allo-HCT setting.

High-dose myeloablative conditioning regimen is not required. Non-myeloablative regimens, capable to completely eradicate the $\mathrm{PNH}$ clone and thus cure $\mathrm{PNH}$, may be preferable in younger patients seeking to maintain fertility or in patients with moderate organ dysfunction who may not tolerate myeloablative doses of chemotherapy. Nonmyeloablative syngeneic bone marrow transplantation did not cure the disease, suggesting

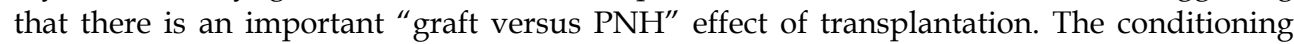
regimen of cyclophosphamide/ATG is recommended for patients with $\mathrm{PNH} /$ aplastic anemia. For patients with classic $\mathrm{PNH}$ a more myeloablative regimen is indicated, eg. 
radiation- or busulfan- based (Parker C et al. 2005). The rationale for use of treosulfanbased conditioning has been its favorably low non-hematological toxicity profile and myeloablative efficiency demonstrated earlier in a dose-finding study (Casper J et al. 2010). It has been reported to be safe and efficient conditioning treatment for PNH (Markiewicz et al. 2005).

The primary objective of the reduced intensity conditioning (RIC) is to achieve stable engraftment of donor cells rather than bone marrow ablation. It provides the potentially curative option for patients with advanced PNH (Hegenbart $U$ et al. 2003). The nonmyeloablative conditioning regimens consisting of fludarabine with either TBI (Grosskreutz C et al. 2003; Hegenbart U et al. 2003), or cyclophosphamide (Takahashi Y et al. 2004) were reported to have adequate potential to eliminate the PNH clone and to allow engraftment. Fludarabine seems to be a highly immunosuppressive nucleoside analogue that has been used in several reduced-intensity conditioning regimens, yielding high engraftment rates with minimal conditioning-related morbidity (Sirinivasan $R$ et al. 2006). Numerous evidence suggests that donor alloimmune effects play a critical role in the eradication of $\mathrm{PNH}$ cells following reduced-intensity conditioning with fludarabine. Importantly, in vitro and in vivo data from patients undergoing fludarabine-based reduced-intensity conditioning have shown that allo-reactive donor T-cells recognizing minor histocompatibility antigens expressed on both normal and GPI-anchored protein negative recipient cells can eradicate PNH (Takahashi Y et al. 2004). At first PNH cells persist following conditioning chemotherapy, then gradual decline of GPI-negative cells takes place followed by conversion to full donor T-cell chimerism and disappearance of residual PNH cells after CsA withdrawal. Minor histocompatibility antigen-specific donor T-cells can be expanded from patients post-transplant with in vitro cytotoxicity against GPI-negative cells of recipient origin. Addition of fludarabine to cyclophosphamide and ATG provides additional host immunosuppression that helps to achieve engraftment in patients at high risk for rejection. It also enables to reduce the traditional dose of cyclophosphamide $(200 \mathrm{mg} / \mathrm{kg})$ without compromising engraftment. Excellent engraftment and long-term survival has been reported in patients with PNH undergoing this reduced-intensity transplant approach (Sirinivasan R, 2006), especially suitable for heavily transfused and/or alloimmunized PNH patients.

Overall survival for unselected PNH patients who undergo transplantation using a HLAmatched sibling donor is in the range of 50 to $60 \%$ (Parker C et al. 2005). Acute GVHD and extensive chronic GVHD are reported as a major complications that may increase treatmentrelated mortality after alloHCT in PNH. Chronic graft-versus host disease (GVHD) is a major complication of patients after allo-HCT. Acute and chronic GVHD after RIC are also seen and may not differ substantially from those occurring after fully ablative transplantation (Grosskreutz C et al. 2003). The combination of methotrexate and cyclosporine A appears to be superior to either agent alone in preventing acute GVHD (Strob R et al. 1986).

\section{Transplant centers' experience}

There are few reports about survival after allogenic transplantation in PNH.

The International Bone Marrow Transplantation Registry reported 2-year survival in recipients of HLA-identical sibling transplantation in years 1978-1995 (median age of 
recipients was 28 years) (Saso $R, 1999)$. Saso et al. described 57 patients who underwent transplantation with myeloablative conditioning from related $(n=50)$ und unrelated $(n=7)$ donors. $19(33,3 \%)$ died within the first 4 months from graft failure (35\%), infection (15\%), GvHD (15\%), bleeding (5\%) and interstitial pneumonitis or acute respiratory distress syndrome $(30 \%)$. The majority of the deaths in this study occurred within one year of transplantation. Long-term survival was 56\% after related and $14 \%$ after unrelated transplantation.

The EBMT (European group for Blood and Marrow Transplantation) has reported 70\% survival after allo-HCT for PNH, but only $54 \%$ met the criteria of classical PNH (Latour RP et al. 2008). Graft failure occurred in $6 \%$ of patients. Acute and chronic GVHD occurred in $15 \%$ and $20 \%$ of patients, respectively. Uni-variant analysis showed better outcome in younger patients (less than 30 years of age) and in patients transplanted less than 2 years from the date of diagnosis (Piccin A et al. 2009).

The GITMO (Gruppo Italiano Trapianto Midollo Osseo) has reported a retrospective study of 26 patients (median age 32 years) with PNH who received allo-HCT between 1988 and 2006 (Santaronr et al. 2010). Median time from diagnosis to transplant was 33 months (range: 3-208 months). HLA-matched sibling donor were used for 22 patients, HLA-matched unrelated donor for 1 patient and 3 patients received cells from HLA-mismatched donors (2 related and 1 unrelated). Myeloablative conditioning regimen (busulfan and cyclophosphamide) has been used in 15 patients and non-myeloablative regimen (treosulfan and cyclophosphamide) in 11 patients. The 10 -year probability of survival was $57 \%$ for all patients with a median follow-up of 131 months. There has been one primary graft failure after myeloablative conditioning regimen and one secondary graft failure in a patient who received RIC allo-HCT. Both died from complications of a second transplant. Acute GVHD greater than stage 2 occurred in 2 of the 26 patients. The cumulative incidence of chronic GVHD in 20 evaluable patients was $50 \%$, in 4 of them chronic GVHD was extensive. Transplant related mortality at one year was $25 \%$ in patients after myeloablative conditioning and $63 \%$ in patients after RIC. Three patients died of multiorgan failure after RIC allo-HCT from non-identical donor. 15 patients are alive with complete hematologic recovery and no evidence of $\mathrm{PNH}$.

21 patients with $\mathrm{PNH}$ or AA/PNH have received allo-HCT after treosulfan-based conditioning in Department of Hematology and BMT of Medical University of Silesia in Katowice, Poland, in years 2004-2011 (see Table 1).

19 allo-HCTs were from 10/10 (15 pts) or 9/10 (4 pts) HLA-matched unrelated donors and 2 from HLA-matched siblings. Median age of recipients was 28 (range 20-51) years and donors 33 (19-53) years, median time from diagnosis to allo-HCT was 16 (2-97) months. Median size of PNH clone was 90\% (4\%-98\%) granulocytes. Indication for allo-HCT was aplastic/hypoplastic bone marrow (11 pts), MDS (1 pt), severe course of PNH with hemolytic crises (5 pts) and transfusion-dependency (in remaining 4 pts). Additional risk factors were Budd-Chiari syndrome and hepatosplenomegaly $(1 \mathrm{pt})$, history of renal insufficiency requiring hemodialyses (2 pts) and chronic hepatitis $B(1 \mathrm{pt})$. The preparative regimen consisted of treosulfan $3 \times 14 \mathrm{~g} / \mathrm{m} 2$ plus fludarabine $5 \times 30 \mathrm{mg} / \mathrm{m} 2$ (19 pts) or treosulfan $2 \times 10 \mathrm{~g} / \mathrm{m} 2$ plus cyclophosphamide $4 \times 40 \mathrm{mg} / \mathrm{kg}$ (2 pts). Standard GVHD prophylaxis consisted of cyclosporine-A, methotrexate and pre-transplant ATG or thymoglobulin in MUD-HCT. Source of cells was bone marrow (9 pts) or peripheral blood (12 pts) with median 2.9 or $11.0 \times 10(8) \mathrm{NC} / \mathrm{kg}$, 2.4 or $6.2 \times 10(6) \mathrm{CD} 34+$ cells $/ \mathrm{kg}, 26.2$ or 266.9 x10(6)CD3+cells $/ \mathrm{kg}$, respectively. Results of alloHCT are presented in Table 2. 


\section{Patient characteristics}

Mean (range)

Age (years)

Patients

$28(20-51)$

Donors

$33(19-53)$

Time from diagnosis to allo-HCT (months)

$16(2-97)$

Number of transplanted cells / $\mathrm{kg}$

Bone marrow
$x 10(8) \mathrm{NC}$
$2.9(0.5-3.9)$
$x 10(6)$ CD34+cells
$2.4(1.2-6.3)$
x10(6) CD3+cells
$26.2(1.6-266.2)$
Peripheral blood
$x 10(8)$ NC
$11.0(4.3-16.5)$
$x 10(6)$ CD34+cells
$6.2(4.1-14.8)$
x10(6) CD3+cells
$266.9(21.9-712.0)$

\begin{tabular}{ll}
\hline & Number of pts \\
\hline Sex & \\
Patients & 15 \\
$\quad$ Men & 6 \\
$\quad$ Women & 12 \\
Donors & 9 \\
$\quad$ Men & \\
$\quad$ Women & \\
& 11 \\
Primary indication for allo-HCT & 1 \\
Aplastic/hypoplastic bone marrow & 5 \\
Myelodysplasia & 4 \\
Severe course of PNH with hemolytic crises & \\
Transfusion-dependency & 2 \\
& \\
Source of transplant & 19 \\
Sibling & \\
Unrelated donor & \\
Source of cells & 9 \\
Bone marrow & 12 \\
Peripheral blood & \\
Regimen & \\
treosulfan $3 \times 14 \mathrm{~g} / \mathrm{m}^{2}$, fludarabine $5 \times 30 \mathrm{mg} / \mathrm{m}^{2}$ & 19 \\
treosulfan $2 \times 10 \mathrm{~g} / \mathrm{m}^{2}$, cyclophosphamide $4 \times 40 \mathrm{mg} / \mathrm{kg}$ & 2 \\
\hline
\end{tabular}

Table 1. Characteristics of donor/recipient pairs and allo-HCT procedures for PNH in Department of Hematology and BMT of Silesian Medical University in Katowice, Poland, experience in years 2004 to 2011. 


\begin{tabular}{ll}
\hline Results & Median (range) \\
\hline Absolute agranulocytosis <0.1 G/1 (days) & $9(6-13)$ \\
Number of transfusions (units) & \\
RBC & $7(0-12)$ \\
Platelets & $6(3-15)$ \\
Regeneration of hematopoiesis (days) & \\
Granulocytes $1.0 \mathrm{G} / 1$ & $17(13-39)$ \\
Platelets $50 \mathrm{G} / 1$ & $17(9-39)$ \\
Hb 10 g/dl & $30(16-50)$ \\
LDH decrease at 30 days post-transplant & $80 \%(5 \%-91 \%)$ \\
\hline
\end{tabular}

Survival at 26 months (2-82) post-transplant

Alive

Died

GVHD

Acute grade I grade II grade III

Chronic, limited

Other complications

FUO

CMV reactivation

Mucositis

VOD

Neurotoxicity

Venal thrombosis

Hemorrhagic cystitis

Achieving $100 \%$ donor chimerism

PNH clone disappearance
$20(95.2 \%)$

1 (previously hemodialysed pt)

Table 2. Results of allo-HCT for PNH in Department of Hematology and BMT of Silesian Medical University in Katowice, Poland, experience in years 2004 to 2011.

Myeloablation was complete in all pts with median 9 (6-13) days of absolute agranulocytosis $<0.1 \mathrm{G} / 1$. Median number of transfused RBC and platelets units was 7(0-12) and 6(3-15). All pts engrafted, median counts of granulocytes $1.0 \mathrm{G} / \mathrm{l}$, platelets $50 \mathrm{G} / 1$ and $\mathrm{Hb} 10 \mathrm{~g} / \mathrm{dl}$ were achieved on days 17(13-39), 16(9-39) and 30(16-50). Acute GVHD grade I,II and III was present in 8, 5 and 1 pt, limited chronic GVHD in 7 pts. LDH decreased by $80 \%(5 \%-91 \%)$ in first 30 days indicating disappearance of hemolysis. 100\% donor chimerism was achieved in all pts. 1 previously hemodialysed pt died on day +102 in a consequence of nephrotoxicity 
complicating adenoviral/CMV hemorrhagic cystitis. Complications in survivors were FUO (5 pts), CMV reactivation (3), VOD (1), neurotoxicity (1), venal thrombosis (1), hemorrhagic cystitis (1) and mucositis (3). 20 pts (95.2\%) are alive 16 months (2-61) post-transplant and are doing well without treatment. Complete disappearance of PNH clone was confirmed by flow cytometry in all surviving patients. We concluded that allo-HCT with treosulfan-based conditioning is effective and well tolerated curative therapy in $\mathrm{PNH}$.

Another novel theoretically interesting approach is related to selection of normal circulating CD34+/CD59+ cells with flow cytometry from $\mathrm{PNH}$ patients who have a mixed population of normal and abnormal cells for the purpose of performing autologous hematopoietic cell transplantation (AHCT). As yet, no case of AHCT for PNH has been reported (Xiao et al. 2010).

\section{Conclusion}

In conclusion, allo-HCT can be offered as an effective treatment option for PNH patients. Transplant-related risk factors for hemolysis can be managed without exacerbation of hemolysis during the procedure. Treosulfan, fludarabine and antithymocyte globulin treatment can be safely and effectively used for conditioning in $\mathrm{PNH}$.

Since the first report of allo-HCT performed in PNH from sibling in 1973, several questions related to $\mathrm{PNH}$ and transplantation remain unresolved. What is the optimal time for alloHCT in PNH? What type of the conditioning therapy- conventional or reduced- enables to achieve durable cure without exacerbation of possible complications? And for what extend benefit of cure offered by alloHCT will defend recommendations for this method in the era of lifelong treatment of the disease with complement inhibitors? We are still looking for answers to these questions.

\section{References}

Bessler M, Hiken J. The Pathophysiology of Disease in Patients with Paroxysmal Nocturnal Hemoglobinuria. Hematology 2008, 104-110.

Bourants K. High dose recombinant human erythropoietin and low dose corticosteroids for treatment of anemia in paroxysmal nocturnal hemoglobinuria. Acta Haematol. 1994; 91: 62-65.

Brodsky RA, Jones RJ. Aplastic anemia. Lancet 2005; 365: 1647-1656.

Brodsky RA. Paroxysmal Nocturnal Hemoglobinuria: the physiology of complementrelated hemolytic anemia. Ann Intern Med. 2008; 148: 587-595.

Brodsky RA, Young NS, Antonioli E, et al. Multicenter phase 3 study of the complement inhibitor eculizumab for the treatement of patients with paroxysmal nocturnal hemoglobinuria. Blood.2008; 111: 1840-1847.

Brodsky RA. How I treat paroxysmal nocturnal hemoglobinuria. Blood 2009, 113, 26; 65226527.

Broekman, M.J., Eiora, A.M \& Marcus, A.J. Inhibition of human platelet reactivity by endothelium- derived relaxing factor from human umbilical vein endothelial cells in suspension: blockade of aggregation and secretion by aspirin-insensitive mechanism. Blood 1991, 78, 1033-1040.

Casper J, wolff D, Knauf W, Blau IW, Rutuu T, Volin L, Wandt H, Schafer-Eckart K, Hołowiecki J, Giebel S, Aschan J, Zander AR, Kroger N, Hilgendorf I, Baumgart J, 
Mylius HA, Pichlmeier U, Freund M. Allogenic hematopoietic stem-cell transplantation in patients with hematologic malignancies after dose-escaleted treosulfan-fludarabine conditioning. J.Clin. Oncol.2010 Jul 10; 28(20): 3344-3351. Epub 2010 May 24. Erratum in: J Clin Oncol. 2010 Aug 10 10;28(23): 3797.

Cho SG, Lim J, Kim Y, Eom HS, Jin CY, Han CW, Kim CC. Conditioning with high-dose cyclophosphamide may not be sufficient to provide a long term remission of paroxysmal nocturnal hemoglobinuria following syngeneic peripheral blood stem cell transplantation. Biol Blood Marrow Transplant. 2003 Jul; 9(7): 453-459.

Corbin, J.D., Francis, S.H \& Webb, D.J. Phosphodiesterase type 5 as a pharmacologic target in erectile dysfunction. Urology 2002, 60, 4-11.

Dunn DE, Tanawattanacharoen P, Boccuni P, Nagakura S, Green SW, Kirby MR, Kumar MS, Rosenfeld S, Young NS. " Paroxysmal nocturnal hemoglobinuria cells in patients with bone marrow failure syndromes. Ann Intern Med. 1999; 131: 401-408.

Epner E, Witherspoon R, Blume K, Storb R. Hematopoietic cell transplantation from related and unrelated donors after minimal conditioning as a curative treatment modality for severe paroxysmal nocturnal hemoglobinuria. Biol Blood Marrow Transplant. 2003 Nov: 9(11): 689-97

Gralnick H.R, Vail, M., McKeown, L.P., Merryman, P., Wilson, O., Chu, I \& Kimball, J . Activated platelets in paroxysmal nocturnal hemoglobinuria BJH 1995; 91: 697-702.

Griffith JF, Mahmoud AE, Cooper S, Elias E, West RJ, Olliff SP. Radiological intervention in Budd-Chiari syndrome: techniques and outcome in 18 patients. Clin Radiol. 1996; 51: 775-784.

Grosskreutz C, Ross V, Scigliano E, Fruchtman S, Isola L. Low dose total body irradiation, fludarabine and antithymocyte globulin conditioning for nonmyeloablative allogeneic transplantation. Biol Blood Marrow Transplant. 2003; 9(7): 453-459

Hall ST, Rosse WF. " The use of monoclonal antibodies and flow cytometry in the diagnosis of paroxysmal nocturnal hemoglobinuria. Blood 1996; 12: 5332-5340.

Hall C, Richard S, Hillmrn P. Primary prophylaxis with warfarin prevents thrombosis in paroxysmal nocturnal hemoglobinuria" Blood 2003: 102: 3587-3591.

Hartmann RC, Jenkins DE Jr, McKee LC, Heyssel RM. Paroxysmal nocturnal hemoglobinuria: clinical and laboratory studies relating to iron metabolism and therapy with androgen and iron. Medicine (Baltimore). 1966; 45: 331-363.

Hegenbart U, Niederwieser D, Forman S, Holler E, Leiblein S, Johnston L, Ponisch Clark DA, Butler SA, Braren V, Hartmann RC, Jenkins DE. The kidneys in paroxysmal nocturnal hemoglobinuria. Blood 1981: 57: 83-89.

Hill A., Wang, X., Sapsford, R.J., McGawley, G.M., Oxborough, D.L., Richards, S.J., Kroon, H., Rother, R.P., Gladwin, M.T., \& Hillmen, P. High prevalence of pulmonary hypertension and hemolysis associated nitric oxide depletion in patients with paroxysmal nocturnal hemoglobinuria (Abstract). Hematologica/ The Hematology Journal 2006, 91, 192.

Hill A, Richards SJ, Hillmen P. Recent developments in the understanding and management of paroxysmal nocturnal haemoglobinuria. British Journal of Haematology 2007, 137; 181-192.

Hillmen P, S.M. Lewis, M. Bessler, L. Luzzatto, and J.V. Dacie. Natural History of Paroxysmal Nocturnal Hemoglobinuria. The New England Journal of Medicine 1995, Vol. 333 No. 19. 1237 -1241. 
Hillmen, P., Young, N.S, Schubert, J., Brodsky R.A., Socie, G., Muus, P., Roth, A., Szer, J., Elebute, M.O, Nakamura, R., Browne, P., Risitano, A.M., Hill, A., Schrezenmeier, H., Fu, C.L., Maciejewski, J., Rollins, S.A., Mojcik, C.F., Rother, R.P \& Luzatto, L. The complement inhibitor eculizumab in paroxysmal nocturnal hemoglobinuria. New England Journal of Medicine, 2006; 355, 1233-1243.

Hillmen P, Muus P, Duhrsen U, Risitano AM, Schubert J, Luzzattio L, Schrezenmeier H, Szer J, Brodsky RA, Hill A, Socie G, Bessler M, Rollins SA, Bell L, Rother RP, Young NS. Effect of the complement inhibitor eculizumab on thromboembolism in patients with paroxysmal nocturnal hemoglobinuria Blood 2007, vol 110, No 12, 4123-4128.

Hillmen P. The role of Complement Inhibition in PNH. Am Soc Hematol Educ Program. 2008: 116-123.

Issaragrisil S, Piankijagum A, Tang-naitrisorana Y. Corticosteroids therapy in paroxysmal nocturnal hemoglobinuria. Am J Hematol.1987; 25: 77-83.

Johnson RJ, P. Hillmen. Paroxysmal nocturnal hemoglobinuria: nature's gene therapy? Clin Pathol 2002; 55: 145-152.

Latour RP, Mary JY, Salanoubat C, Terriou L, Etienne G, Mohty M, Roth S, de Guibert S, Maury S, Cahn JY, Socie G, French Society of Hematology; French Association of Young Hematologists. Paroxysmal nocturnal hemoglobinuria: natural history of disease subcategories. Blood 2008; 112(8): 3099-3106. Epub 2008 Jun 5

Lee JL, Lee JH, Lee Jh, Choi SJ, Kim S, Seol M, Lee YS, Chi Hs, Park Cj, Kim WK, Lee JS, Lee $\mathrm{KH}$. Allogenic hematopoietic cell transplantation for paroxysmal nocturnal hemoglobinuria. Eur. J Haematol. 2003. 71(2) 114-118.

Markiewicz M, Wojciechowska M, Wyleżoł I, Giebel S, Wożniczka K, Wojnar J, MendekCzajkowska E, Hołowiecki J. First two successful unrelated donor bone marrow transplantations for paroxysmal nocturnal hemoglobinuria in Poland Annals of Transplantation 2005, 10(3), 26-30.

Markiewicz M, Wojciechowska M, Wyleżoł I, Woźniczka K, Giebel S, Wojnar J, KrawczykKuliś M, Mendek-Czajkowska E, Hołowiecki J: Unrelated donor bone marrow transplantation with treosulfan-based myeloablative conditioning for paroxysmal nocturnal hemoglobinuria- successful treatment despite multiple transplant-related risk factors for hemolysis including major Kidd group incompatibility. Bone Marrow Transplant 2006, 37(2), 231-232.

Matozs-Fernandez NA, Abou Mourad YR, Caceres W, Kharfan-Dabaja MA. Current status of allogenic hematopoietic stem cell transplantation for paroxysmal nocturnal hemoglobinuria. Biol Blood Marrow Transplant. 2009. 15(6): 656-661.

McMullin MF, Hillmen P, Jackson J, Ganly P, Luzatto L, Tissue plasminogen activator for hepatic vein thrombosis in paroxysmal nocturnal hemoglobinuria. J. Intern Med. 1994: 235: 85-89.

Moyo VM, Mukhina GL, Garret ES, Brodsky RA, “Natural History of paroxysmal nocturnal hemoglobinuria using modern diagnostic assays" Br. J. Haematol. 2004; 126: 133-138

Mukhina GL, Buckley JT, Barber JP, Jones RJ, Brodsky RA. "Multilineage glycosylphosphatidylinositol anchor deficient hematopoiesis in untreated aplastic anemia. Br J Haematol. 2001; 115: 476-482

Nagarajan S, Brodsky RA, Young NS, Medof ME. Genetic defects underlying paroxysmal nocturnal hemoglobinuria that arises out of aplastic anemia Blood. 1995; 86: 4656-4661. 
Nishimura JI, Kanakura Y, Ware RE, Schichishima T, Nakakuma H, Ninomiya H., Decastro CM, Hall S, Kanamaru A, Sullivan Km, Mizoquchi H, Omine M, Kinishita T, Rosse WF. Clinical course and flow cytometric analysis of paroxysmal nocturnal hemoglobinuria In the United States and Japan. Medicine 2004; 83: 193-207.

Parker CJ. An overview of the development of specific inhibitors of complement: opportunites for therapy of paroxysmal nocturnal hemoglobinuria. In: Omnie M, Kinoshita T, eds. Paroxysmal nocturnal hemoglobinuria and Related Disorders: Molecular Aspects of Pathogenesis. Tokyo: Springer; 2003: 11-23.

Parker C, Mitsuhiro O, Stephen Richards, Jun-ichi Nishimura, Monica Bessler, Russler Ware, Peter Hillmen, Lucio Luzatto, Neal Young, Taroh Kinoshita, Wendell Rose, and Gerard Socie, for the International PNH Interest Group. Diagnosis and management of paroxysmal nocturnal hemoglobinuria Blood 2005, vol 106, No 12; 3699-3708.

Parker Charles J. Paroxysmal Nocturnal Hemoglobinuria: an Historical Overview. Hematology 2008, 93-103.

Piccin A McCann S, Socie G, Oneto R, Bacigalupo A, Locasciulli A, Marsh J, Schrezenmeier H, Tichelli A, Hand E, Lawler M, Passweg J, Aplastic Anemia Party of the European Group for Blood and Marrow transplantation. Survival of patients with documented autologus recovery after SCT for severe aplastic anemia, a study by the WPSAA of the EBMT. Bone Marrow Transplant. 2010. 45(6): 1008-1013.

Raiola AM, Van Lint MT, Lamparelli T, Gualandi F, Benventuro F, Figari O, Mordini N, Berissa G, Bregante S, Frassoni F, Bacigalupo A. Bone marrow transplantation for paroxysmal nocturnal hemoglobinuria. Haematologica. 2000. 85(1) 59-62.

Rosse WF. Treatment of paroxysmal nocturnal hemoglobinuria Blood.1982; 60-23.

Rosse WF. Paroxysmal nocturnal hemoglobinuria. In Hoffman R, Benz EJ, Shattil SJ, et al. eds. Hematology: Basic principials and Practice. New York: Churhill Livingstone; 2000:331-342

Rosse WF, Peter Hillmen, Alan D. Schreiber. Immune mediated hemolytic anemia. Hematology 2004:48-6219.

Russell P, Rother, PhD; Leonard bell, MD; Peter Hillmen, MB; PhD, Mark T, Gladwin MD. The clinical sequeale of intravascular hemolysis and extracellular plasma hemoglobin. A novel mechanism of human disease. JAMA 2005; 293: 1653-1662.

Santaronr S, Bacigalupo A, Risitano AM, Tagliaferri E, Di Bartolomeo E, Iori AP, Rambaldi A, Angelucci E, Spagnoli A, Papineschi F, Tammiazo S, Di Nicola M, Di Bartolomeo P. Hematopoietic stem cell transplantation for paroxysmal nocturnal hemoglobinuria: long-term results of a retrospective study on behalf of the Gruppo Italiano Trapianto Midollo Osseo (GITMO). Haematologica. 2010; 95(6): 983-988.

Saso R, Marsh J, cevreska L, Szer J, Gale RP, Rowlings PA, Passweg JR, Nugent ML, Luzzatto L, Horwitz MM, Gordon-Smith EC. Bone Marrow transplants for paroxysmal nocturnal haemoglobinuria. Br J Haematol. 1999; 104(2): 396-396.

Schafer, A., Wiesman, F., Neubauer, S., Eigenthaler, M., Bauersachs, J. \& Channon, K.M. $(2004)$ Rapid regulation of platelet activation in vivo by nitric oxide. Circulation, $109,1819-1822$.

Schrezenmeier H, Hertenstein B, Wagner B, Raghavachar A, Heimpel H, A pathogenetic link between aplastic anemia and paroxysmal nocturnal hemoglobinuria is suggested by a high frequency of aplastic anemia patients with deficiency of phosphatidylinositol glycan anchored proteins" Exp. Hematol. 1995:23: 81-87 
Sholar PW, Bell WR. Thrombolytic therapy for inferior vena cava thrombosis in paroxysmal nocturnal hemoglobinuria. Ann Intern Med. 1985; 103: 539-541

Sirinivasan R, Takahashi Y, McCoy JP, Espinoza- Delgado I, Dorrance C, Igarashi T, Lundqvist A, Barrett AJ, Young NS, Geller N, Childs RW. Overcoming graft rejection in heavily transfused and allo-immunised patients with bone- marrow failure syndromes using fludarabine-based haematopoietic cell transplantation. Br. J. Haematol. 2006: 133(3): 305-314.

Sloand EM, Young NS. Thrombotic complications in PNH. In: Young NS, Moss J, eds. Paroxysmal Nocturnal Hemoglobinuria and Glycosylphosphatidylinositol- Linked Proteins. San- Diego, CA Academic Press; 2000: 101-112.

Socie G, Marry JY, de Gramont A, Rio, B., Leporrier, M., Rose, C., Heudier, P., Rochant, H., Cahn, J.Y. \&Gluckman, E. “ Proxysmal nocturnal hemoglobinuria: long-term follow-up and prognostic factors" French Society of Haematology. Lancet. 1996; 348: 573-577.

Socie G, Hillmen P, Muus P,et al. Sustained improvements in transfusion requirements, fatique and thrombosis with eculizumab treatement in paroxysmal nocturnal hemoglobinuria. Blood 2007: 110 Abstract 3672.

Strob R, Deeg HJ, Farwell V, Doney K, Appelbaum F, Baetty P, Bensinger W, Buskner CD, Clift R, Hansen J, et al. Marrow Transplantation for severe aplastic anemia: metothrexate alone compared with combination of metothrexate and cyclosporine for prevention of acute graft-versus host disease. Blood 1986 Jul;68(1): 119-25

Suenaga K, Kanda Y, Niiya H, Nakai K, Satio A, Ohnishi M, Takeuchi T, Tanosaki R, Makimoto A, Miyawaki S, Ohnishi T, Kanai S, Tobinai K, Takaue Y, Mineishi S, Successful application of nonmyeloablative transplantation for paroxysmal nocturnal hemoglobinuria. Exp. Hematol 2001 May 29(5): 639-642

Sugimori C Chuhjo T, Feng X, et al. Minor population of CD55- blood cells predicts response to immunosuppressive therapy and prognosis in patients with aplastic anemia. Blood 2006; 107: 1308-1314.

Tabbara, I.A. (1992) Hemolytic anemias. Diagnosis and management. Medical Clinics of North America, 76, 649-668.

Takahashi Y, McCoy JP Jr, Carvallo C, Rivera C, igarashi T, Srinivasan R, Young NS, Childs RW. In vitro and in vivo evidence of PNH cell sensitivity to immune attack after nonmyeloablative allogeneic hematopoietic cell transplantation. Blood.2004, 103(4): 1383-90.

Wang H, Chuhjo T, Yasue S, Omine M, Nakao S. Clinical significance of a minor population of paroxysmal nocturnal hemoglobinuria- type cells in bone marrow failure syndrome. Blood 2002; 100: 3897-3902.

Ware RE, Hall SE, Rosse WF. " Paroxysmal nocturnal hemoglobinuria with onset in childhood and adolescence. N Engl J Med. 1992; 325: 991-996.

Woodard P, Wang W, Pitts N, Benaim E, Horwitz E, Cunningham J, Bowman L. Succesful unrelated donor bone marrow transplantation for paroxysmal nocturnal hemoglobinuria. Bone Marrow Transplant. 2001 Mar. 27(6) 589-92.

Xiao J, Han B, Wu YJ, Zhong YP, Sun WL. Ex vivo expansion and long-term hematopoietic reconstitution ability of sorted CD34+, CD59+ cells from patients with paroxysmal nocturnal hemoglobinuria. Int J Hematol. 2010. 92(1): 58-67.

Young NS. Acquired aplastic anemia. Ann Intern Med. 2002; 136: 534-546.

Zhao M, Shao Z. Li K, et al. Clinical analysis of 78 cases of paroxysmal nocturnal hemoglobinuria diagnosed in the past ten years Chin Med J (Engl) 2002; 115: 398-401. 


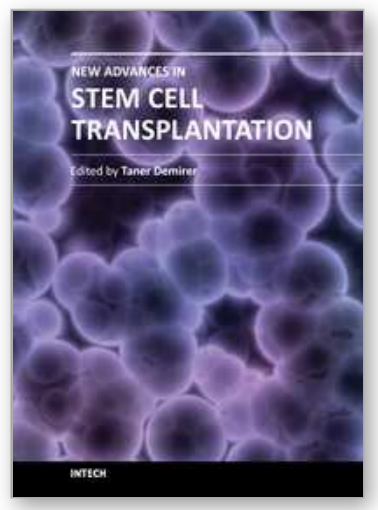

\author{
New Advances in Stem Cell Transplantation \\ Edited by Prof. Taner Demirer
}

ISBN 978-953-51-0013-3

Hard cover, 582 pages

Publisher InTech

Published online 24, February, 2012

Published in print edition February, 2012

This book documents the increased number of stem cell-related research, clinical applications, and views for the future. The book covers a wide range of issues in cell-based therapy and regenerative medicine, and includes clinical and preclinical chapters from the respected authors involved with stem cell studies and research from around the world. It complements and extends the basics of stem cell physiology, hematopoietic stem cells, issues related to clinical problems, tissue typing, cryopreservation, dendritic cells, mesenchymal cells, neuroscience, endovascular cells and other tissues. In addition, tissue engineering that employs novel methods with stem cells is explored. Clearly, the continued use of biomedical engineering will depend heavily on stem cells, and this book is well positioned to provide comprehensive coverage of these developments.

\title{
How to reference
}

In order to correctly reference this scholarly work, feel free to copy and paste the following:

Markiewicz Miroslaw, Koclega Anna, Sobczyk-Kruszelnicka Malgorzata, Dzierzak-Mietla Monika, Zielinska Patrycja, Frankiewicz Andrzej, Bialas Krzysztof and Kyrcz-Krzemien Slawomira (2012). Allogeneic Hematopoietic Cell Transplantation for Paroxysmal Nocturnal Hemoglobinuria, New Advances in Stem Cell Transplantation, Prof. Taner Demirer (Ed.), ISBN: 978-953-51-0013-3, InTech, Available from: http://www.intechopen.com/books/new-advances-in-stem-cell-transplantation/allogeneic-hematopoietic-celltransplantation-for-paroxysmal-nocturnal-hemoglobinuria

\section{INTECH}

open science | open minds

\section{InTech Europe}

University Campus STeP Ri

Slavka Krautzeka 83/A

51000 Rijeka, Croatia

Phone: +385 (51) 770447

Fax: +385 (51) 686166

www.intechopen.com

\section{InTech China}

Unit 405, Office Block, Hotel Equatorial Shanghai

No.65, Yan An Road (West), Shanghai, 200040, China

中国上海市延安西路65号上海国际贵都大饭店办公楼 405 单元

Phone: +86-21-62489820

Fax: $+86-21-62489821$ 
(C) 2012 The Author(s). Licensee IntechOpen. This is an open access article distributed under the terms of the Creative Commons Attribution 3.0 License, which permits unrestricted use, distribution, and reproduction in any medium, provided the original work is properly cited. 